the treated animals. Although the medical significance of this finding is questionable, this information adds to the biological characterization of this class of compounds.

The relative antineoplastic activity of the other aflatoxin fractions has yet to be determined.

I thank Mr Rubizoll Terry for technical assistance.

Sidney Green

Cell Biology Branch,

Division of Nutrition,

Food and Drug Administration,

Department of Health, Education and Welfare, Washington.

Received August 27, 1968.

${ }^{1}$ Lancaster, M. C., Jenkins, F. P., and Philip, J. McL., Nature, 192, 1095 (1961).

${ }^{2}$ Butler, W. H., and Barnes, J. M., Brit. J. Cancer, 17, 699 (1964).

${ }^{3}$ Butler, W. H., in Mycotoxins in Foodstuffs (edit. by Wogan, G. N.), 175 (MIT Press, Cambridge, 1965).

${ }^{4}$ Sporn, M. B., Dingman, W. C., and Wogan, G. N., Science, 151, 1539 (1966).

${ }^{5}$ Newberne, P. M., Pathol. Vet.,1, 105 (1964).

- DiPaolo, J. A., Elis, J., and Erwin, H., Nature, 215, 638 (1967).

${ }^{7}$ Legator, M., Bact. Rev., 30, 471 (1966).

${ }^{8}$ Dolimpio, D., Jacobson, C., and Legator, M., Proc. Soc. Exp. Biol. and Med., $127,559(1968)$.

\section{Effects of Habituation to Fear on the Exploratory Behaviour of Rats}

I PROPOSED earlier ${ }^{1,2}$ that mild fear facilitates exploratory behaviour whereas strong fear inhibits it. If an animal is placed in a maze, with time it bocomes habituated to the fear aroused by the maze stimuli. It is therefore to be expected that, at first, strong fear will inhibit the exploratory behaviour of rats, but with time the foar should become milder and exploratory behaviour will be facilitated. Eventually the lovel of fear of the rats should be minimal and exploratory behaviour of the rats will sink to somo base level.

A good measure of exploratory behaviour is the orderliness of the behaviour. (Activity measures of exploration are confused by the general activity of the animals ${ }^{3,4}$.) Orderlincss of exploration can be investigated by placing rats in a $\mathrm{Y}$ maze and noting the sequence of arms cntered by cach rat. 'This technique has been used and described by Montgomory ${ }^{5}$ and myself ${ }^{6}$. The experiment reported here was designed to investigate tho variation in the orderliness of Y maze exploration by rats over a period of time.

Eighty 120-124 day old naive male rats of tho Charles River Broeding Laboratories strain CD were housed in single cages. The animals were placed either in an enclosed $\mathrm{Y}$ maze or on a raised $\mathrm{Y}$ maze. The mazes were made of wood and had arms 22 inches long and 6 inches wide. Tho enclosed maze was 6 inches deep and was covered with wire netting.

The rats were kept without food for either 0 or $24 \mathrm{~h}$. There were four groups of twenty rats. Nine rats fell off the raised maze and their data were discarded. Each rat was placed in the $\mathrm{Y}$ maze for $20 \mathrm{~min}$ and the sequence of arms entered by the rat was noted. An entry was defined as having been made when all four paws of the rat had entered one arm. The rats were not handled during the 20 min exploratory test.

The orderliness of the rats' exploratory behaviour was calculated for each $5 \mathrm{~min}$ period of the $20 \mathrm{~min}$ test. For rats on raised mazes the orderliness was significantly higher in the middle two periods of the 20 min exploratory test (on a Friedman two-way analysis of variance? $\left.\chi^{2}=8.72, \quad d f=3, \quad P<0.05\right)$. Of the thirty-one rats, eightcon showed maximum orderliness during the middle $10 \mathrm{~min}$ of the exploratory test, and eight had their maxi- mum orderliness in the first or the final $5 \mathrm{~min}$. (Five rats could not be classified into this dichotomy.) This difference is significant on a binomial test $(z=1 \cdot 65$, onetailed $P=0.047$ ). The median scores of the rats during each $5 \mathrm{~min}$ interval are shown in Table 1 . For the rats which were run in enclosed mazes, there was no significant trend in the orderliness over the four 5 min periods. (On a Friedman two-way analysis of variance, $\chi^{2}=5 \cdot 20, d f=3$, $P>0 \cdot 10$.) Of the forty rats, sixteen had their maximum orderliness during the middle $10 \mathrm{~min}$ of the exploratory test, and twenty had their maximum orderliness during the initial or final $5 \mathrm{~min}$. (Four rats could not be classified into this dichotomy.) This difference was not significant in a binomial test. The variable of deprived versus not deprived had no effect on these results.

Table 1. THE MEDIAN ORDERTINESS OF THE RATS IN ELEVATED AND ENCLOSED MAZES FOR EACH 5 MIN PERIOD OY THE EXPLORATORY TEST

(The orderliness seore is the percentage of alternation rather than repetition of choices made by the rats.)

$\begin{array}{cccc}\text { First } & \text { Second } & \text { Third } & \text { Fourth } \\ \text { period } & \text { period } & \text { period } & \text { period } \\ 60 \cdot 0 \% & 66.7 \% & 80 \cdot 0 \% & 66.7 \% \\ 66.7 \% & 66.7 \% & 66.7 \% & 66.7 \%\end{array}$

Raised unaze Enclosed maze $60 \cdot 0 \%$ $66 \cdot 7 \%$ $80.0 \%$

The results obtained with the rats placed on the raised maze support the prediction of an inverted U-shaped function for the orderliness of exploratory behaviour over a period of time. Rats which were placed in the enclosed maze appeared to explore with uniform ordor. liness. This makes good sense. Rats which were placed on raised mazes appeared to be more emotional than rats placed in enclosed mazes ${ }^{5,8}$. Thus the rats on the raised maze presumably have a high level of fear at tho start of the exploratory test and this will inhibit their exploratory behaviour. In time this fear dissipates and the exploratory behaviour becomes more orderly. The rats placed in the enclosed maze presumably do not have such a high level of fcar aroused by the maze at first, and so their exploratory behaviour is not inhibited to the same extent as the rats on the elevated maze.

It is possible that the results obtained are an artefact of the number of choices made by the rats in each $5 \mathrm{~min}$ period of the exploration test. For example, the reduced orderliness of exploration under high fear could simply be a result of the long intervals of time between choices (possibly because of freezing by the rats), causing some forgetting of the previous choice. That this is unlikely is suggested by the fact that, for the raised rats, the median number of arm entries made in the first period was eight and the median orderliness was $60 \cdot 0$ por cent; for the third period, the median number of arm entries was six and the median orderliness was 80.0 per cent. These data are the opposite of what would be expected if the results were an artefact of the number of choices made by the rats in each period of the exploration test.

The finding of a U-shaped function here is supported by findings from my other experiments ${ }^{9}$ which obtained similar functions between exploratory behaviour and variables, reflecting changes in the levels of fear in very different conditions.

David Lester

Department of Psychology,

Wellesley College,

Wollesley, Massachusetts.

Received September 4; revised October 14, 1968.

${ }^{1}$ I ester, D., Prychol. Rec., 17', 55 (1907)

'Lester, D., J. Gen. Psychol., 79, 105 (1968).

3 Sheldon, M. H., Psychon. Sci.,11, 38 (1968).

${ }^{4}$ Lester, D., Psychon. Sci. (in the press).

s Montgomery, K. C., J. Comp. Physiol. Psychol., 48, 254 (1055).

${ }^{6}$ Lester, D., Psychon. Sci., 8, 7 (1967).

'Siegel, S., Nonparametric Statistics for the Behavioral Sciences (McGraw-Hill, 1056 ).

${ }^{8}$ Lester, D., Psychon. Sci., 9, 117 (1967).

'Lester, D., Psychon. Sci., 10, 385 (1968). 